\title{
La vacunación contra el virus del papiloma humano redujo el riesgo de cáncer invasor del cuello uterino
}

\author{
Human papillomavirus vaccination reduced the risk of invasive cervical cancer
}

\section{Comentado de:}

Lei J, et al. N Engl J Med 2020; 383(14):1340-1348. PMID: 32997908 doi: 10.1056/NEJMoa1917338a ${ }^{1}$

\section{Objetivo}

Evaluar la asociación entre la vacunación contra el virus del papiloma humano (VPH) y el riesgo de desarrollar cáncer invasor del cuello uterino.

\section{Diseño, lugar, fuente de datos y población}

Cohorte retrospectiva abierta, realizada en el Instituto Karolinska, Suecia. A partir de los registros nacionales de ese país, fueron seleccionadas mujeres y niñas sin diagnóstico de cáncer invasor del cuello uterino residentes en Suecia desde antes del 01/06/2006, que entre enero de 2006 y diciembre de 2017 tenían entre 10 y 30 años de edad, y que al momento de ingresar a la cohorte no hubieran recibido la vacuna contra el VPH.

\section{Intervención}

Aplicación de al menos una dosis de la vacuna tetravalente contra el VPH durante el periodo de estudio.

\section{Medición de resultados principales}

Incidencia de cáncer de cuello uterino ajustada por edad, condado de residencia, año calendario, país de nacimiento materno, máximo nivel educativo alcanzado por los padres, nivel de ingreso familiar anual más alto, y diagnóstico materno previo de neoplasia intraepitelial cervical (CIN) grado 3 o mayor $(\mathrm{CIN} 3+)$ y de otros cánceres.

\section{Resultados Principales}

Fueron incluidas 1.672 .983 mujeres y niñas, de las cuales 527.871 (31,6\%) habían sido vacunadas.

En el grupo de las vacunadas fueron analizados dos subgrupos de manera independiente: las $438.939(83,2 \%)$ vacunadas antes de los 17 años y las 88.932 (16,8\%) vacunadas entre los 17 y los 30 años.

En el grupo de las no vacunadas fueron diagnosticados 538 casos de cáncer del cuello uterino y en el grupo de las vacunadas, 19 casos. De estos últimos, sólo casos dos fueron diagnosticados en el grupo de las vacunadas antes de los 17 años, y 17 casos entre quienes fueron vacunadas entre los 17 y los 30 años.

La Tabla 1 muestra los resultados principales.

Tabla 1. Incidencia y reducción del riesgo de cáncer invasor del cuello uterino en mujeres y niñas suecas de acuerdo a su estatus y edad de vacunación contra el VPH. Notas: IC: intervalo de confianza. *Ajuste realizado por edad, condado de residencia, año calendario, país de nacimiento materno, máximo nivel educativo alcanzado por los padres, nivel de ingresos familiares, diagnóstico materno previo de $\mathrm{CIN} 3+$ y diagnóstico materno de otros cánceres.

\begin{tabular}{|l|c|c|c|}
\hline Estado de vacunación contra el VPH & $\begin{array}{l}\text { Incidencia cruda de cáncer } \\
\text { invasor de cuello uterino/ } \\
100.000 \text { personas-año (IC 95\%) }\end{array}$ & $\begin{array}{l}\text { Razón de tasas de incidencia } \\
\text { ajustada (IC 95\%) }\end{array}$ & $\begin{array}{c}\text { Reducción de riesgo de } \\
\text { cáncer invasor del cuello } \\
\text { uterino, \% (IC 95\%) }\end{array}$ \\
\hline No vacunadas & $5,27(4,84$ a 5,73) & referencia & referencia \\
\hline Vacunadas & $0,73(0,47$ a 1,14) & $0,37(0,21$ a 0,57$)$ & 63 (43 a 79$)$ \\
\hline Vacunadas antes de los 17 años & $0,10(0,02$ a 0,39$)$ & $0,12(0,00$ a 0,34$)$ & $88(66$ a 100) \\
\hline Vacunadas entre los 17 y los 30 años & $3,02(1,88$ a 4,86) & $0,47(0,27$ a 0,75$)$ & 53 (25 a 73) \\
\hline
\end{tabular}

\section{Conclusiones}

La vacuna tetravalente contra el VPH administrada en niñas y mujeres suecas entre los 10 y los 30 años de edad estuvo asociada a un menor riesgo de padecer cáncer invasor del cuello uterino, con una mayor disminución documentada en edades más tempranas.

Fuente de financiamiento/Conflicto de interés de los autores: Tres autores trabajan para Merk, el laboratorio que produce la vacuna contra el VPH tetravalente $\left(\right.$ Gardasil $^{\circledR}$ ) y un autor trabaja para Swedish Cancer Society, Swedish Foundation for Strategic Research y Swedish Research Council, tres instituciones suecas que financiaron el proyecto de investigación.

\section{Comentario}

La vacuna tetravalente (disponible desde 2006) ha demostrado prevenir tanto la infección por VPH como las lesiones intraepiteliales de alto grado; sin embargo, según la evidencia disponible hasta el momento, su efecto sobre la prevención del cáncer invasor del cuello uterino todavía no era concluyente ${ }^{2,3}$.

Algunas de las fortalezas de este estudio incluyen su tamaño muestral considerable, el seguimiento a 12 años y que sus resultados son contundentes. Dentro de las limitaciones es importante remarcar que los autores decidieron ajustar los resultados por ciertas variables demográficas y de salud materna (ver Tabla 1) sin justificar el porqué de su selección y sin explicitar el modelo causal. Uno de los cuestionamientos que surgen en este punto es preguntarnos ¿qué resultados se hubieran obtenido si se hubieran realizado ajustes por aquellos factores de riesgo bien conocidos para el cáncer invasor del 
cuello uterino (p. ej., edad de inicio de relaciones sexuales, tabaquismo, inmunosupresión, obesidad, entre otros) ${ }^{4,5}$, cuya información es mucho más difícil de obtener a partir de bases de datos de recolección rutinaria a nivel nacional como las usadas en este trabajo?

Otra de las limitaciones del estudio es la presencia del sesgo del voluntario sano. Podríamos esperar que las niñas y mujeres con hábitos más saludables tengan tasas más altas de vacunación y, a su vez, presenten una menor incidencia de cáncer invasor del cuello uterino, y no quedaría claro en qué medida la disminución del riesgo de cáncer se debe a sus hábitos saludables o a la vacunación. Asimismo, podríamos suponer que quienes tienen hábitos más saludables serán quienes más concurran a realizarse el rastreo de cáncer de cuello uterino, y podríamos esperar que en este grupo se detecten más casos.

\section{Conclusiones de la comentadora}

Más allá de las consideraciones metodológicas mencionadas, que suelen ser difíciles de evitar en este tipo de investigaciones que utilizan información de grandes bases de datos, este estudio aporta nueva información muy relevante y contundente sobre el efecto protector de la vacuna del VPH frente al desarrollo del cáncer cervicouterino.

Sobre la base de sus resultados, parece razonable recomendar a las niñas y a mujeres menores de 30 años -preferiblemente antes de los 17-, la aplicación de la vacuna tetravalente contra este agente viral.

Malena Chiaborelli [ Servicio de Medicina Familiar y Comunitaria, Hospital Italiano de Buenos Aires. malena.chiaborelli@hospitalitaliano.org.ar ]

Chiaborelli M. La vacunación contra el virus del papiloma humano redujo el riesgo de cáncer invasor del cuello uterino. Evid Actual Pract Ambul. 2021;24(3):e002148. Available from: https://dx.doi.org/10.51987/EVIDENCIA.V24I4.6969. Comentado de: Lei J, et al. HPV Vaccination and the Risk of Invasive Cervical Cancer. N Engl J Med 2020; 383(14):1340-1348. PMID: 32997908 doi: 10.1056/NEJMoa1917338a

\section{Referencias}

1. Lei J, Ploner A, Elfström KM, et al. HPV Vaccination and the Risk of Invasive Cervical Cancer. N Engl J Med. 2020;383(14):1340-1348. Available from: 10.1056/NEJMoa1917338.

2. Luostarinen T, Apter D, Dillner J, et al. Vaccination protects against invasive HPV-associated cancers. Int J Cancer. 2018;142(10):2186-2193. Available from: $10.1002 /$ ijc. 31231 .

3. Guo F, Cofie LE, Berenson AB. Cervical Cancer Incidence in Young U.S. Females After Human Papillomavirus Vaccine Introduction. Am J Prev Med. 2018;55(2):197-204. Available from: 10.1016/j.amepre.2018.03.013.

4. Poorolajal J, Jenabi E. The association between BMI and cervical cancer risk: a meta-analysis. Eur J Cancer Prev. 2016;25(3):232-238. Available from: 10.1097/CEJ.0000000000000164

5. Plummer M, Herrero R, Franceschi S, et al. Smoking and cervical cancer: pooled analysis of the IARC multi-centric case-control study. Cancer Causes Control. 2003;14(9):805-814. Available from: 10.1023/b:caco.0000003811.98261.3e. 